\title{
Appication of ahp and topsis method for supplier selection problem
}

\author{
${ }^{1}$ Pema Wangchen Bhutia, Ruben Phipon ${ }^{2}$ \\ ${ }^{1,2}$ Department of Mechanical Engineering Sikkim Manipal Institute of Technology Sikkim, India
}

\begin{abstract}
Supplier selection, the process of determining the suitable suppliers who are able to provide the buyer with the right quality products and/or services at the right price, at the right time and in the right quantities, is one of the most critical activities for establishing an effective supply chain. In other words, supplier selection is a multi-criteria decision making problem which includes both qualitative and quantitative factors. In order to choose the best suppliers, it is essential to make a trade-off between these tangible and intangible factors, some of which may conflict. The aim of this study is to develop a methodology to evaluate suppliers in supply chain cycle based on Technique for Order Preference by Similarity to Ideal Solution method (TOPSIS). In this paper, I have taken into consideration some important criteria which affect the process of supplier selection, that is, product quality, service quality, delivery time and price. I have calculated the weights for each criterion based on Analytic Hierarchy Process (AHP) and then inputted these weights to the TOPSIS method to rank suppliers. The entire methodology is illustrated with the help of a numerical example and finally the rank of each supplier is determined according to its results.
\end{abstract}

Keywords-Analytic Hierarchy Process (AHP), multi-criteria decision making, supplier selection, Technique for Order Preference by Similarity to Ideal Solution method (TOPSIS)

\section{INTRODUCTION}

In order to maintain a competitive position in the global market, organizations have to follow strategies to achieve shorter lead times, reduced costs and higher quality. Therefore, suppliers play a key role in achieving corporate competitiveness, and as a result of this, selecting the right suppliers is a critical component of these new strategies.

Several conflicting quantitative and qualitative factors or criteria like cost, quality, delivery etc. affect supplier selection problem. Therefore, it is a multi-criteria decision making problem that includes both quantitative and qualitative factors, some of which conflict to each other.

Increases and varieties of customer demands, advances of recent technologies in communication and information systems, competition in global environment, decreases in governmental regulations, and increases in environmental consciousness have forced companies to focus on supply chain management. The "supply chain management" term has been used for almost 20 years and is defined as the integration of activities to procure materials, their transformation into intermediate goods and final products, and delivery to customers. In supply chains, coordination between a manufacturer and suppliers is typically a difficult and important link in the channel of distribution. Once a supplier becomes part of a well-managed and established supply chain, this relationship will have a lasting effect on the competitiveness of the entire supply chain. Because of this, supplier selection problem has become one of the most important issues for establishing an effective supply chain system. Besides, selection of suppliers is a complicated process by the facts that numerous criteria must be considered in the decision making process. Research results indicate that supplier selection process is one of the most significant variables, which has a direct impact on the performance of an organization. As the organization becomes more and more dependent on their suppliers, the direct and indirect consequences of poor decision making will become more critical. The nature of this decision is usually complex and unstructured. On the other hand, supplier selection decision making problem involves trade-offs among multiple criteria that involve both quantitative and qualitative factors, which may also be conflicting.

In this paper, we have identified some effective criteria which affect the process of supplier selection. Based on Analytic Hierarchy Process (AHP), we have calculated the weights for each criterion and inputted those weights to the TOPSIS method to rank suppliers. The main advantages of using TOPSIS method are:-

1. It is simple to use.

2. It takes into account all types of criteria (subjective and objective).

3. It is rational and understandable.

4. The computation processes are straight forward. 
5. The concept permits the pursuit of best alternatives criterion depicted in a simple mathematical calculation.

\section{LITERATURE REVIEW}

The objective of supplier selection is to identify suppliers with the highest potential for meeting a firm's needs consistently. Weber et al. (1991) assessed 74 supplier selection papers from 1966 to 1991, and illustrated that nearly $63 \%$ of them were in a multi-criteria decision making situation. In the past, several methodologies have been proposed for supplier selection problem. Weber and Ellram (1993) developed the use of a multi-objective programming approach as a method for supplier selection in just in time (JIT) setting. Weber and Current (1993) used multi-objective linear programming for supplier selection to systematically analyze the trade-off between conflicting criteria. In this model, aggregate price, quality and late delivery are considered as goals. Ghodsypour and O'Brien (1998) proposed integration of an AHP and linear programming to consider both tangible and intangible factors in choosing the best suppliers and placing optimum order quantities among them. They also presented a mixed integer non-linear programming model to solve the multiple sourcing problems, with multiple criteria and with supplier's capacity. Chaudhry et al. (1991) have used integer goal programming to solve the problem of allocating order quantities among suppliers. Karpak and Kasuganti (1999) have used visual interactive goal programming for supplier selection process. Liu et al. (2000) used data envelopment analysis (DEA) to compare the performance evaluation of different supplier for best selection. Kumar et al. (2002) have used fuzzy mixed integer goal programming for supplier selection problem. Wang et al. (2004) used the advantages of AHP and preemptive goal programming to incorporate both quantitative and qualitative factor in supplier selection problem. Bhutta amd Huq (2002) have illustrated and compared the technique of total cost of ownership and AHP in supplier selection process. Chan et al. (2007) applied an AHP to determine the optimal supplier. His model evaluated the suppliers based on 14 criteria. Wadhwa and Ravindran (2007) proposed a supplier selection methodology that consists of 3 objectives, such as price, lead time and rejects. All of these objective functions are minimization. Vahdani et al. (2008) also presented a three step methodology based on balancing and ranking methods in supplier evaluation.

Hong et al. (2005) formulated a mixed integer linear programming model for the suppliers' assessment. The model provides jointly, "optimal order quantity" and "optimal number of suppliers". Narasimhan et al. (2006) developed a multi objective programming model to indicate the best supplier and the optimal order quantity. Mendoza and Venture (2008) utilized a two step method to solve supplier selection problem. At the first step, AHP was used to rank and decrease number of supplier. At the second step, the mixed integer non linear programming model was applied to determine the optimal order quantity. $\mathrm{Ng}$ (2008) presented a weighted linear programming model for supplier evaluation. His proposed model is based on maximizing the suppliers' score.

Chang (1996) introduced a new extent analysis approach for the synthetic extent values of the pair wise comparison for handling fuzzy AHP (FAHP). The proposed FAHP with extent analysis is simple and easy for implementation to prioritize decision variables as compared with the conventional AHP. Chen (2001) presented a multiple-criteria decision-making model based on fuzzy-set theory for supplier selection. Kahraman et al. (2003) used the fuzzy AHP for domestic supplier selection with only 3 criteria and 11 attributes and neglected the many important criteria which create the uncertainty in supplying the products, that is, the risk factors involved in global supplier selection. Chiou et al. (2005) used a fuzzy hierarchical analytic process to determine the weights of criteria from subjective judgments and a non-additive integral technique to evaluate the performance of sustainable development strategies for aquatic products processors. Beside these approaches, Amiri et al. (2008) presented a multivariate approach for solving supplier selection problem. His approach is based on principal component analysis that used information obtained from Eigenvector to combine different ratio measures defined by every input and output.

\section{TOPSIS METHOD}

TOPSIS method was introduced for the first time by Yoon and Hwang and was appraised by surveyors and different operators. TOPSIS is a decision making technique. It is a goal based approach for finding the alternative that is closest to the ideal solution. In this method, options are graded based on ideal solution similarity. If an option is more similar to an ideal solution, it has a higher grade. Ideal solution is a solution that is the best from any aspect that does not exist practically and we try to approximate it. Basically, for measuring similarity of a design (or option) to ideal level and non-ideal, we consider distance of that design from ideal and non-ideal solution.

General TOPSIS process with 7 steps is listed below:- 


\section{Step 1}

Form a decision matrix. The structure of the matrix can be expressed as follows:

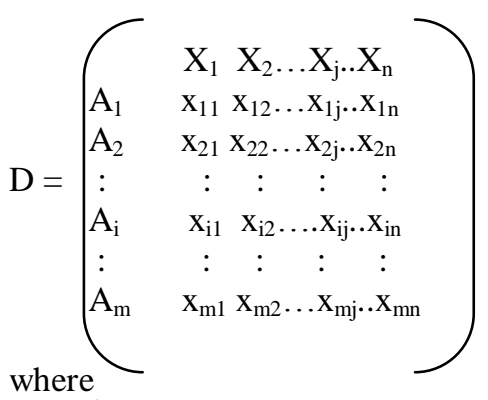

$\mathrm{A}_{\mathrm{i}}=\mathrm{i}^{\text {th }}$ alternative projects

$X_{i j}=$ the numerical outcome of the $i^{\text {th }}$ alternative projects with respect to $j^{\text {th }}$ criteria

\section{Step 2}

Normalize the decision matrix D by using the following formula:

$\mathrm{r}_{\mathrm{ij}}=\mathrm{x}_{\mathrm{ij}} / \sqrt{\mathrm{i}=1} \mathrm{n} \mathrm{x}_{\mathrm{ij}}^{2}$

\section{Step 3}

Construct the weighted normalized decision matrix by multiplying the normalized decision matrix by its associated weights. The weighted normalized value $\mathrm{v}_{\mathrm{ij}}$ is calculated as:

$\mathrm{v}_{\mathrm{ij}}=\mathrm{w}_{\mathrm{ij}} \mathrm{r}_{\mathrm{ij}}$

\section{Step 4}

Determine the positive ideal solution and negative ideal solution.

$\mathrm{A}^{*}=\left\{\left(\max v_{\mathrm{ij}} \mid j \in J\right),\left(\min v_{\mathrm{ij}} \mid j \in \mathrm{J}^{\prime}\right)\right\}$

$\mathrm{A}^{-}=\left\{\left(\min v_{\mathrm{ij}} \mid \mathrm{j} \in J\right),\left(\max v_{\mathrm{ij}} \mid j \in J^{\prime}\right)\right\}$

$\mathrm{J}=1,2,3, \ldots, \mathrm{n}$

where $\mathrm{J}$ is associated with the benefit criteria

$\mathrm{J}^{\prime}=1,2,3, \ldots, \mathrm{n}$

where $\mathrm{J}^{\prime}$ is associated with the cost criteria

\section{Step 5}

Calculate the separation measure.

The separation of each alternative from the positive ideal one is given by:

$\mathrm{S}_{\mathrm{i}}^{*}=\sqrt{ } \sum_{\mathrm{j}=1}^{\mathrm{n}}\left(\mathrm{V}_{\mathrm{ij}}-\mathrm{V}_{\mathrm{j}}\right)^{2}$

where $\mathrm{i}=1,2, \ldots, \mathrm{m}$

Similarly, the separation of each alternative from the negative ideal one is given by:

$\mathrm{S}_{\mathrm{i}}^{-}=\sqrt{ } \sum_{\mathrm{j}=1}^{\mathrm{n}}\left(\mathrm{v}_{\mathrm{ij}} \mathrm{-}_{\mathrm{j}}^{-}\right)^{2}$

where $\mathrm{i}=1,2, \ldots, \mathrm{m}$

\section{Step 6}

Calculate the relative closeness to the ideal solution.

The relative closeness of $A_{i}$ with respect to $A^{*}$ is defined as:

$\mathrm{C}_{\mathrm{i}}^{*}=\mathrm{S}_{\mathrm{i}}^{-} /\left(\mathrm{S}_{\mathrm{i}}^{*}+\mathrm{S}_{\mathrm{i}}^{-}\right), \quad 0 \leq \mathrm{C}_{\mathrm{i}}^{*} \leq 1$

where $i=1,2, \ldots, m$

The larger the $\mathrm{C}_{\mathrm{i}}{ }^{*}$ value, the better the performance of the alternatives. 
Step 7

Rank the preference order.

\section{Analytic Hierarchy Process (AHP)}

The Analytic Hierarchy Process is a procedure designed to quantify managerial judgments of the relative importance of each of several conflicting criteria used in the decision making process. In this paper, we have used the following steps of AHP to help us to measure the relative importance or the weighted values of several criteria.

Step 1

List the overall goal, criteria and decision alternatives.

Step 2

Develop a pairwise comparison matrix.

Step 3

Develop a normalized matrix.

Step 4

Develop the priority vector.

Step 5

Rank the preferred criteria.

\section{PROPOSED METHODOLOGY}

The proposed methodology for supplier selection problem, composed of TOPSIS method, consists of three steps. These are:

1. Identify the criteria to be used in the model.

2. Weight the criteria by using AHP.

3. Evaluation of alternatives with TOPSIS and determination of the final rank.

In the first step, we try to recognize variables and effective criteria in supplier

selection and the criteria which will be used in their evaluation is extracted. Thereafter, list of qualified suppliers are determined. In the second step, we assign weights to each criterion by using AHP. Finally, ranks are determined using TOPSIS method in the third step.

\section{NUMERICAL EXAMPLE, CALCULATION AND RESULTS}

In this section, to implement the methodology, we have solved simulated numerical example. Assume that the management of a manufacture wants to choose their best suppliers. Based on proposed methodology, 3 steps are applied for assessment and selection of suppliers. In this part, we deal with application of these steps. We are going to evaluate 30 suppliers $(\mathrm{A} 1, \mathrm{~A} 2, \mathrm{~A} 3, \ldots \ldots . ., \mathrm{A} 30)$ as alternatives against product quality $(\mathrm{X} 1)$, service quality (X2), delivery time (X3) and price $(\mathrm{X} 4) . \mathrm{X} 1, \mathrm{X} 2$ and $\mathrm{X} 3$ are benefit attributes and $\mathrm{X} 4$ is cost attribute. The following table 1.1 gives us a list of suppliers and their respective attributes.

Table 1.1 showing various suppliers and their respective attributes

\begin{tabular}{|c|l|l|l|l|}
\hline $\begin{array}{l}\text { Supplier } \\
\text { Alternatives }\end{array}$ & $\begin{array}{l}\text { Product Quality } \\
(\mathrm{X} 1)\end{array}$ & $\begin{array}{l}\text { Service Quality } \\
(\mathrm{X} 2)\end{array}$ & Delivery Time (X3) & Price (X4) \\
\hline A1 & Extremely Good & Good & Very Fast & High \\
\hline A2 & Good & Good & Very Fast & Extremely High \\
\hline A3 & Extremely Good & Very Good & Very Fast & High \\
\hline A4 & Very Good & Very Good & Extremely Fast & Very High \\
\hline A5 & Good & Extremely Good & Fast & Very High \\
\hline A6 & Extremely Good & Extremely Good & Fast & Very High \\
\hline A7 & Extremely Good & Good & Fast & Extremely High \\
\hline A8 & Very Good & Extremely Good & Extremely Fast & Very High \\
\hline A9 & Extremely Good & Very Good & Fast & Very High \\
\hline A10 & Good & Very Good & Extremely Fast & Very High \\
\hline A11 & Good & Extremely Good & Extremely Fast & High \\
\hline A12 & Good & Good & Extremely Fast & Extremely High \\
\hline
\end{tabular}


Appication of ahp and topsis method for supplier selection problem

\begin{tabular}{|l|l|l|l|l|}
\hline A13 & Very Good & Good & Very Fast & Extremely High \\
\hline A14 & Good & Extremely Good & Very Fast & Very High \\
\hline A15 & Extremely Good & Very Good & Fast & Extremely High \\
\hline A16 & Extremely Good & Very Good & Very Fast & Extremely High \\
\hline A17 & Very Good & Extremely Good & Very Fast & Extremely High \\
\hline A18 & Good & Extremely Good & Very Fast & High \\
\hline A19 & Extremely Good & Good & Extremely Fast & High \\
\hline A20 & Good & Very Good & Very Fast & Extremely High \\
\hline A21 & Good & Very Good & Extremely Fast & High \\
\hline A22 & Very Good & Extremely Good & Extremely Fast & High \\
\hline A23 & Extremely Good & Extremely Good & Very Fast & High \\
\hline A24 & Extremely Good & Very Good & Fast & High \\
\hline A25 & Very Good & Extremely Good & Fast & Extremely High \\
\hline A26 & Good & Good & Extremely Fast & Very High \\
\hline A27 & Very Good & Very Good & Very Fast & Extremely High \\
\hline A28 & Very Good & Good & Extremely Fast & High \\
\hline A29 & Extremely Good & Very Good & Very Fast & Very High \\
\hline A30 & Good & Extremely Good & Very Fast & Extremely High \\
\hline
\end{tabular}

Ten point scale chosen for above attributes are:

$\mathrm{X} 1 \& \mathrm{X} 2$

Good -5

Very Good -7

Extremely Good -9
$\mathrm{X} 4$

High -5

Very High -7

Extremely High -9
Fast -5

$\mathrm{X} 3$

Very Fast -7

Extremely Fast -9

Table 1.2 showing the structure of a decision matrix

\begin{tabular}{|c|c|c|c|c|}
\hline $\begin{array}{l}\text { Supplier } \\
\text { Alternatives }\end{array}$ & Product Quality (X1) & Service Quality (X2) & Delivery Time (X3) & Price (X4) \\
\hline A1 & 9 & 5 & 7 & 5 \\
\hline A2 & 5 & 5 & 7 & 9 \\
\hline A3 & 9 & 7 & 7 & 5 \\
\hline A4 & 7 & 7 & 9 & 7 \\
\hline A5 & 5 & 9 & 5 & 7 \\
\hline A6 & 9 & 9 & 5 & 7 \\
\hline A7 & 9 & 5 & 5 & 7 \\
\hline A8 & 7 & 9 & 9 & 7 \\
\hline A9 & 9 & 7 & 5 & 5 \\
\hline A10 & 5 & 7 & 9 & 9 \\
\hline A12 & 5 & 9 & 9 & 7 \\
\hline A13 & 5 & 5 & 9 & 9 \\
\hline A14 & 7 & 5 & 7 & 9 \\
\hline A15 & 5 & 9 & 7 & 5 \\
\hline A17 & 9 & 7 & 5 & 5 \\
\hline A18 & 9 & 7 & 7 & 9 \\
\hline A19 & 7 & 9 & 7 & 5 \\
\hline A20 & 5 & 9 & 7 & 5 \\
\hline A21 & 9 & 5 & 9 & 5 \\
\hline A22 & 5 & 7 & 7 & 5 \\
\hline A23 & 5 & 7 & 9 & 9 \\
\hline A24 & 9 & 9 & 9 & 9 \\
\hline A25 & 9 & 9 & 7 & 5 \\
\hline A26 & 7 & 7 & 5 & 9 \\
\hline A27 & 5 & 9 & 5 & 9 \\
\hline A29 & 7 & 5 & 9 & 7 \\
\hline A30 & 9 & 7 & 9 & 7 \\
\hline
\end{tabular}

Table 1.3 gives the normalized values of the decision matrix 


\begin{tabular}{|c|c|c|c|c|}
\hline $\begin{array}{l}\text { Supplier } \\
\text { Alternatives }\end{array}$ & $\begin{array}{l}\text { Product } \quad \text { Quality } \\
\text { (X1) }\end{array}$ & $\begin{array}{ll}\text { Service } & \text { Quality } \\
(\mathrm{X} 2) & \end{array}$ & Delivery Time (X3) & Price $(\mathrm{X} 4)$ \\
\hline A1 & .2280 & .1239 & .1738 & .1257 \\
\hline A2 & .1267 & .1239 & .1738 & .2263 \\
\hline A3 & .2280 & .1734 & .1738 & .1257 \\
\hline $\mathrm{A} 4$ & .1773 & .1734 & .2235 & .1760 \\
\hline A5 & .1267 & .2229 & .1242 & .1760 \\
\hline A6 & .2280 & .2229 & .1242 & .1760 \\
\hline A7 & .2280 & .1239 & .1242 & .2263 \\
\hline A8 & .1773 & .2229 & .2235 & .1760 \\
\hline A9 & .2280 & .1734 & .1242 & .1760 \\
\hline A10 & .1267 & .1734 & 2235 & .1760 \\
\hline A11 & .1267 & .2229 & .2235 & .1257 \\
\hline A12 & .1267 & .1239 & 2235 & .2263 \\
\hline A13 & .1773 & .1239 & .1738 & .2263 \\
\hline A14 & .1267 & .2229 & .1738 & .1760 \\
\hline A15 & .2280 & .1734 & .1242 & .2263 \\
\hline A16 & .2280 & .1734 & .1738 & .2263 \\
\hline A17 & .1773 & .2229 & .1738 & .2263 \\
\hline A18 & .1267 & .2229 & .1738 & .1257 \\
\hline A19 & .2280 & .1239 & .2235 & .1257 \\
\hline $\mathrm{A} 20$ & .1267 & .1734 & .1738 & .2263 \\
\hline A21 & .1267 & .1734 & .2235 & .1257 \\
\hline A22 & .1773 & .2229 & .2235 & .1257 \\
\hline A23 & .2280 & .2229 & .1738 & .1257 \\
\hline A24 & 2280 & .1734 & .1242 & .1257 \\
\hline A25 & .1773 & .2229 & .1242 & .2263 \\
\hline A26 & .1267 & .1239 & 2235 & .1760 \\
\hline A27 & .1773 & .1734 & .1738 & .2263 \\
\hline A28 & .1773 & .1239 & .2235 & .1257 \\
\hline A29 & .2280 & .1734 & .1738 & .1760 \\
\hline A30 & .1267 & .2229 & .1738 & .2263 \\
\hline
\end{tabular}

Using AHP, we calculate the weighted values for each criterion as follows:

Table 1.4 showing the numerical rating for various statements

Assumption

\begin{tabular}{|l|l|}
\hline $\begin{array}{l}\text { Compared to the } 2^{\text {nd }} \text { alternative, the } 1^{\text {st }} \\
\text { alternative is: }\end{array}$ & Numerical Rating \\
\hline Extremely preferred & 9 \\
\hline Very strongly preferred & 7 \\
\hline Strongly preferred & 5 \\
\hline Moderately preferred & 3 \\
\hline Equally preferred & 1 \\
\hline
\end{tabular}

For supplier selection problem let us assume:

1. Product quality is moderately preferred, strongly preferred and very strongly preferred to service quality, price and delivery time respectively.

2. Service quality is moderately preferred and strongly preferred to price and delivery time respectively.

3. Price is moderately preferred to delivery time.

Performing different steps of AHP

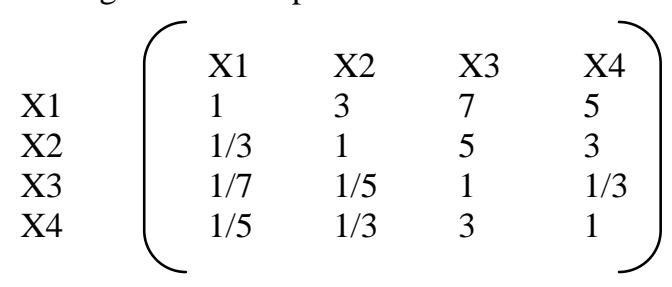




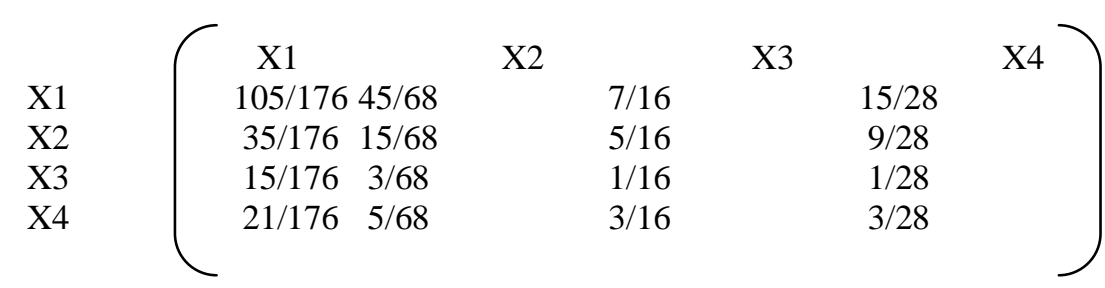

$\mathrm{X} 1:(105 / 176+45 / 68+7 / 16+15 / 28) / 4=.5579(\mathrm{w} 1)$

$\mathrm{X} 2:(35 / 176+15 / 68+5 / 16+9 / 28) / 4=.2633$ (w2)

$\mathrm{X} 3:(15 / 176+3 / 68+1 / 16+1 / 28) / 4=.0569(\mathrm{w} 3)$

$\mathrm{X} 4:(21 / 176+5 / 68+3 / 16+3 / 28) / 4=.1219(\mathrm{w} 4)$

Table 1.5 shows the weighted normalized decision matrix

\begin{tabular}{|c|c|c|c|c|}
\hline $\begin{array}{l}\text { Supplier } \\
\text { Alternatives }\end{array}$ & $\begin{array}{l}\text { Product Quality } \\
\text { (X1) }\end{array}$ & $\begin{array}{l}\text { Service Quality } \\
\text { (X2) }\end{array}$ & Delivery Time (X3) & Price $(\mathrm{X} 4)$ \\
\hline A1 & .1272 & .0326 & .0099 & .0153 \\
\hline A2 & .0707 & .0326 & .0099 & .0276 \\
\hline A3 & .1272 & .0457 & .0099 & .0153 \\
\hline $\mathrm{A} 4$ & .0989 & .0457 & .0127 & .0215 \\
\hline A5 & .0707 & .0587 & .0071 & .0215 \\
\hline A6 & .1272 & .0587 & .0071 & .0215 \\
\hline A7 & .1272 & .0326 & .0071 & .0276 \\
\hline A8 & .0989 & .0587 & .0127 & .0215 \\
\hline A9 & .1272 & .0457 & .0071 & .0215 \\
\hline A10 & .0707 & .0457 & .0127 & .0215 \\
\hline A11 & .0707 & .0587 & .0127 & .0153 \\
\hline A12 & .0707 & .0326 & .0127 & .0276 \\
\hline A13 & .0989 & .0326 & .0099 & .0276 \\
\hline A14 & .0707 & .0587 & .0099 & .0215 \\
\hline A15 & .1272 & .0457 & .0071 & .0276 \\
\hline A16 & .1272 & .0457 & .0099 & .0276 \\
\hline A17 & .0989 & .0587 & .0099 & .0276 \\
\hline A18 & .0707 & .0587 & .0099 & .0153 \\
\hline A19 & .1272 & .0326 & .0127 & .0153 \\
\hline $\mathrm{A} 20$ & .0707 & .0457 & .0099 & .0276 \\
\hline A21 & .0707 & .0457 & .0127 & .0153 \\
\hline A22 & .0989 & .0587 & .0127 & .0153 \\
\hline A23 & .1272 & .0587 & .0099 & .0153 \\
\hline A24 & .1272 & .0457 & .0071 & .0153 \\
\hline A25 & .0989 & .0587 & .0071 & .0276 \\
\hline A26 & .0707 & .0326 & .0127 & .0215 \\
\hline A27 & .0989 & .0457 & .0099 & .0276 \\
\hline A28 & .0989 & .0326 & .0127 & .0153 \\
\hline A29 & .1272 & .0457 & .0099 & .0215 \\
\hline $\mathrm{A} 30$ & .0707 & .0587 & .0099 & .0276 \\
\hline
\end{tabular}

Table 1.6 showing the positive ideal solution and the negative ideal solution

\begin{tabular}{|c|c|c|c|c|}
\hline & $\mathrm{X} 1$ & $\mathrm{X} 2$ & $\mathrm{X} 3$ & $\mathrm{X} 4$ \\
\hline $\mathrm{A}^{*}$ & .1272 & .0587 & .0127 & .0153 \\
\hline $\mathrm{A}-$ & .0707 & .0326 & .0071 & .0276 \\
\hline
\end{tabular}


Table 1.7 showing the separation measures, the relative closeness coefficient and the ranking of different

\begin{tabular}{|c|c|c|c|c|}
\hline Suppliers & $\mathrm{Si}^{*}$ & $\mathrm{Si}^{-}$ & $\mathrm{Ci}^{*}$ & Rank \\
\hline A1 & $\mathrm{S} 1 *=.0262$ & $\mathrm{~S}^{-}=.0579$ & $\mathrm{C} 1 *=.6885$ & 10 \\
\hline A2 & $\mathrm{S} 2 *=.0635$ & $\mathrm{~S}^{-}=.0028$ & $\mathrm{C} 2 *=.0422$ & 30 \\
\hline A3 & $\mathrm{S} 3 *=.0133$ & $\mathrm{~S}^{-}=.0594$ & $\mathrm{C} 3 *=.8171$ & 3 \\
\hline A4 & $\mathrm{S} 4 *=.0318$ & $\mathrm{~S} 4^{-}=.0322$ & $\mathrm{C} 4 *=.5031$ & 16 \\
\hline A5 & $\mathrm{S}^{*}=.0571$ & $\mathrm{~S}^{-}=.0268$ & $\mathrm{C} 5^{*}=.3194$ & 23 \\
\hline A6 & S6 $*=.0084$ & $\mathrm{~S}^{-}=.0625$ & $\mathrm{C6}^{*}=.8815$ & 2 \\
\hline A7 & $\mathrm{S} 7 *=.0294$ & $\mathrm{~S}^{-}=.0565$ & $\mathrm{C} 7 *=.6577$ & 11 \\
\hline A8 & $\mathrm{S} 8 *=.0290$ & $\mathrm{~S}^{-}=.0393$ & $\mathrm{C} 8 *=.5754$ & 13 \\
\hline A9 & S9* $=.0155$ & $\mathrm{~S}^{-}=.0583$ & $\mathrm{C} 9 *=.7900$ & 6 \\
\hline A10 & $\mathrm{S} 10^{*}=.0583$ & $\mathrm{~S} 10^{-}=.0155$ & $\mathrm{C} 10^{*}=.2100$ & 26 \\
\hline A11 & $\mathrm{S} 11^{*}=.0565$ & $\mathrm{~S} 11^{-}=.0294$ & $\mathrm{C} 11 *=.3423$ & 20 \\
\hline A12 & $\mathrm{S} 12^{*}=.0634$ & $\mathrm{~S} 2^{-}=.0056$ & $\mathrm{C} 12 *=.0812$ & 29 \\
\hline A13 & $\mathrm{S} 13^{*}=.0405$ & $\mathrm{~S} 13^{-}=.0283$ & $\mathrm{C} 13 *=.4113$ & 19 \\
\hline A14 & $\mathrm{S} 14^{*}=.0569$ & $\mathrm{~S} 14^{-}=.0269$ & $\mathrm{C} 14^{*}=.3210$ & 22 \\
\hline A15 & $\mathrm{S} 15^{*}=.0188$ & $\mathrm{~S} 15^{-}=.0580$ & $\mathrm{C} 15^{*}=.7552$ & 8 \\
\hline A16 & $\mathrm{S} 16^{*}=.0181$ & $\mathrm{~S} 16^{-}=.0581$ & $\mathrm{C} 16^{*}=.7625$ & 7 \\
\hline A17 & $\mathrm{S} 17^{*}=.0310$ & $\mathrm{~S} 17^{-}=.0385$ & $\mathrm{C} 17^{*}=.5540$ & 14 \\
\hline A18 & $\mathrm{S} 18^{*}=.0566$ & $\mathrm{~S} 18^{-}=.0290$ & $\mathrm{C} 18^{*}=.3388$ & 21 \\
\hline A19 & $\mathrm{S} 19^{*}=.0261$ & $\mathrm{~S} 19^{-}=.0581$ & $\mathrm{C} 19 *=.6900$ & 9 \\
\hline A20 & $\mathrm{S} 20^{*}=.0593$ & $\mathrm{~S} 20^{-}=.0134$ & $\mathrm{C} 20^{*}=.1843$ & 27 \\
\hline A21 & $\mathrm{S} 21^{*}=.0580$ & $\mathrm{~S} 21^{-}=.0188$ & $\mathrm{C} 21 *=.2448$ & 25 \\
\hline A22 & $\mathrm{S} 22 *=.0283$ & $\mathrm{~S} 22^{-}=.0407$ & $\mathrm{C} 22 *=.5899$ & 12 \\
\hline A23 & $\mathrm{S} 23^{*}=.0028$ & $\mathrm{~S} 23^{-}=.0635$ & $\mathrm{C} 23^{*}=.9578$ & 1 \\
\hline A24 & $\mathrm{S} 24^{*}=.0142$ & $\mathrm{~S} 24^{-}=.0593$ & $\mathrm{C} 24 *=.8068$ & 4 \\
\hline A25 & $\mathrm{S} 25^{*}=.0314$ & $\mathrm{~S} 25^{-}=.0384$ & $\mathrm{C} 25^{*}=.5501$ & 15 \\
\hline A26 & $\mathrm{S} 26^{*}=.0625$ & $\mathrm{~S} 26^{\circ}=.0083$ & $\mathrm{C} 26^{*}=.1172$ & 28 \\
\hline A27 & $\mathrm{S} 27^{*}=.0336$ & $\mathrm{~S} 27^{-}=.0312$ & $\mathrm{C} 27^{*}=.4815$ & 17 \\
\hline A28 & $\mathrm{S} 28^{*}=.0385$ & $\mathrm{~S} 28^{-}=.0313$ & $\mathrm{C} 28 *=.4484$ & 18 \\
\hline A29 & $\mathrm{S} 29^{*}=.0147$ & $\mathrm{~S} 29^{-}=.0584$ & $\mathrm{C} 29 *=.7989$ & 5 \\
\hline A30 & $\mathrm{S} 30^{*}=.0579$ & $\mathrm{~S} 30^{-}=.0262$ & $\mathrm{C} 30^{*}=.3115$ & 24 \\
\hline
\end{tabular}

\section{CONCLUSION}

In supply chains, co-ordination between a manufacturer and suppliers is typically a difficult and important link in the channel of distribution. This paper presents a multi-criteria decision making for evaluation of supplier by implementing TOPSIS method. This method is simple to understand and permits the pursuit of best alternatives criterion depicted in a simple mathematical calculation.

Due to this, decision making for selection of suitable supplier is of special importance. Acquired results from numerical example determine that this model could be used for decision making optimization in supplier selection.

\section{References}

[1] Application of multi-criteria decision making technique to evaluation of suppliers in supply chain management by Amir Naderi and Mohammad Saeed Zaeri

[2] A review of methods supporting supplier selection by Luitzen de Boer, Eva Labro and Pierangela Morlacchi

[3] TOPSIS method for supplier selection problem by Omid Jadidi, Fatemeh Firouzi and Enzo Bagliery

[4] TOPSIS extension for multi-objective supplier selection problem under price breaks by Omid Jadidi, Tang Sai Hong and Fatemeh Firouzi

[5] Comparison of weights in TOPSIS models by D.L. Olson

[6] TOPSIS-AHP simulation model and its application to supply chain management by Min Wu

[7] Application of TOPSIS in the bidding evaluation of manufacturing enterprises by Li Hao and Xie Qing-sheng

[8] A TOPSIS method-based approach to machine tool selection by Vijay Manikrao Athawale and Shankar Chakraborty 